\title{
PILAR MIRÓ Y EL REVIVAL DEL NOIR EN LOS NOVENTA: BELTENEBROS Y LA FEMME FATALE EN PROCESO DE DE(CON)STRUCCIÓN
}

\author{
EVA PARÍs-HuESCA
}

Ohio Wesleyan University

Pilar Miró ha marcado el inicio de unas pautas en el nuevo cine negro de autoría femenina. Su proyecto fílmico Beltenebros desafía algunas de las convenciones visuales y narrativas más representativas que refuerzan el arquetipo de la femme fatale, redefiniendo los roles de(l) género y cuestionando la mirada tradicional masculina. A pesar del escaso reconocimiento que la directora ha recibido en el nuevo cine negro español, su trayectoria fílmica la convierte en una de las pioneras de este género multiforme en su vertiente más retro-noir. Asimismo, el film saca a relucir los diferentes modos de violencia que el patriarcado ejerce sobre el cuerpo femenino y facilita el proceso de desmasculinización del cine negro por medio del juego de intertextos y de referencias metafílmicas que privilegian un discurso femenino.

PALABRAS CLAVE: castración, referencias metafílmicas, desmasculinización, Zeitgeist, imagen extrafílmica.

Pilar Miro and the revival of noir in the nineties: Beltenebros and the femme fatale in the process of de(con)struction

Pilar Miró has created new paradigms in neo-noir cinema made by women. Her filmic project Beltenebros challenges some of the most typical visual and narrative conventions that have reinforced the femme fatale archetype. She has thus re-defined gender/genre roles, questioning the traditional male gaze. Despite the filmmaker's lack of recognition in Spanish neo-noir cine$\mathrm{ma}$, she is a pioneer in this multifaceted genre, particularly in the development of a retro-noir variant. Furthermore, her film brings to light the different forms of violence that patriarchy exerts on the female body. It also facilitates the process of demasculinization of noir cinema by means of an intertextual and metafilmic referential exercise that privileges female discourse.

KEY WORDS: castration, metafilmic references, demasculinization, Zeitgeist, extrafilmic image.

Pilar Miró es la primera cineasta y mujer nombrada Directora General de Cinematografía (1982-1985), debido a su fuerte compromiso con la política socialista y a su interés por despolitizar los medios de comunicación. Su cine, al igual que el de sus coetáneas Josefina Molina y Cecilia Bartolomé, se resiste al

París-Huesca, Eva (2015), "Pilar Miró y el revival del noir en los noventa: Beltenebros y la femme fatale en proceso de de(con)strucción", Lectora, 21: 45-58. ISSN: 1136-5781 D.O.I.: 10.1344/105.000002024, eparish@owu.edu

Recepció: 1 de juny de 2014 - Acceptació: 15 de juliol de 2014 
discurso patriarcal que discrimina al sujeto femenino, subordina sus roles frente a los del hombre y legitima una lógica androcéntrica que busca controlar y coaccionar el cuerpo de la mujer. La adaptación de textos canónicos de las letras españolas, alemanas y francesas es para Pilar Miró una estrategia de legitimación cultural y un filtro a través del cual construye ficciones que incluyen experiencias de la mujer y le otorgan un espacio privilegiado en la historia. La realizadora asegura en una larga entrevista llevada a cabo por Diego Galán, y emitida hace años por TVE, que todas las películas tienen algo de su director(a) y no es del todo necesario que el guión sea obra de él (o de ella) para que en el producto final existan huellas claras de su autoría (Galán, 2006: 303). En el contexto que nos ocupa aquí, la directora madrileña explota las fórmulas visuales, estéticas y narrativas de la ficción neo-noir, siguiendo una estética retro-noir, ${ }_{1}^{1}$ para llevar la novela Beltenebros (Muñoz Molina, 1989) a su terreno personal, convirtiendo el espacio fílmico en una vía catártica para expresar un trauma particular y una preocupación nacional.

A lo largo de su carrera, Pilar Miró se enfrenta a numerosos obstáculos. Su esfuerzo por despolitizar, democratizar y modernizar la industria fílmica y televisiva la convierten en víctima de denuncias y amenazas por parte de los integrantes del partido socialista, así como del sexismo imperante en el mundo profesional en el que se mueve. Las consecuencias son graves: en diciembre de 1985 dimite de su cargo como Directora de Cinematografía del Ministerio de Cultura, tras las duras críticas recibidas por las medidas proteccionistas que adopta en el cine español. En 1989 renuncia a su cargo como Directora General de Radiotelevisión Española, a raíz de las acusaciones por malversación de fondos que la llevan a un juicio doloroso pero del que sale triunfante. La decepcionante falta de concreción de los ideales formulados durante los años ochenta y la desilusión con una política democrática socialista corrupta e incapaz de promover verdaderas transformaciones sociopolíticas acentúan su visión crítica y amarga, que culmina en proyectos novedosos y atrevidos como Beltenebros. La adaptación de la obra homónima de Antonio Muñoz Molina le da la oportunidad de expresar su desencanto, como mujer políticamente comprometida con el partido socialista, y su resentimiento hacia aquellos que, siendo miembros del mismo partido y amigos en los que confiaba, la subestimaron, juzgaron y traicionaron. ${ }^{2}$

\footnotetext{
${ }^{1}$ El formato retro-noir permite reconstruir el periodo bélico y represivo con una estética más atractiva. El objetivo es darle una dimensión utópica a un pasado no resuelto que se concibe como un tiempo en el que existieron unos ideales políticos claros y un sentido de unidad moral e ideológica que ya no existen en la actualidad (Jordan y Morgan-Tamasunas, 2001: 37 ).

${ }^{2}$ Su siguiente film Tu nombre envenena mis sueños también sigue las pautas del retro-noir y es fruto de un encargo directo que Pilar Miró hace al escritor Joaquín Leguina, a quien le pide que escriba una novela sobre una mujer cuyo deseo principal es matar a sus enemigos y vengar la muerte de su amante (Galán, 2006: 85).
} 
Las páginas que siguen se centran en la representación fílmica de los dos personajes femeninos que aparecen en cada uno de los viajes de Darman a Madrid. La primera figura es Rebeca Osorio, una escritora comprometida con la lucha antifranquista y la segunda es la joven Rebeca, ${ }^{3}$ "la prostituta más cara de Madrid". En el plano superficial, estas dos mujeres funcionan como marcadores de una identidad fílmica supeditada a los paradigmas formales, estilísticos y narrativos del neo-noir. Sin embargo, un análisis profundo de las estrategias empleadas por Pilar Miró para de(con)struir el arquetipo de la femme fatale revela la existencia de un nuevo espacio femenino de significación, resistencia y denuncia. De gran importancia en este proceso de(con)structivo son las referencias metafílmicas, que van más allá de lo que Wendy Rolph (1995) concibe como un juego posmoderno de espejos entre los personajes femeninos de Beltenebros y sus antecedentes fílmicos y literarios. Como veremos a continuación, las constantes referencias a Gilda y al texto literario Rebecca, de Daphne de Maurier, y a la adaptación fílmica de King Vidor, junto al contexto histórico-político en que cada una de estas historias se inserta, facilitan la recuperación de una imagen positiva y transgresora de la mujer en el plano diegético y extradiegético. Por último, las intertextualidades le asignan un rol importante al sujeto espectatorial, que participa de forma activa y crítica en el proceso de subversión y deconstrucción del mito de la femme fatale y, por consiguiente, contribuye al acto de desmasculinización del neo-noir. Como indica Linda Hutcheon, para cuando el neo-noir se establece en la España cultural posmoderna, el espectador ya ha aceptado las convenciones tanto estéticas como ideológicas del cine negro clásico (1988: XII), con lo cual el proceso de desexuar la mirada y desexualizar ${ }^{4}$ la imagen de la mujer para devolverle su identidad como sujeto depende en gran medida de la capacidad del espectador para descodificar estos signos visuales, intertextuales y narrativos e interpretar el texto fílmico en toda su complejidad.

\footnotetext{
${ }^{3}$ Las similitudes en el nombre, el parecido físico y otras coincidencias establecen una relación (real y/o simbólica) entre las dos Rebecas (la joven Rebeca es un espejo de la Rebeca del pasado de Darman) que cumple varias funciones. Entre ellas, está la repetición de la historia y el sentido de imposibilidad de cambiar su rumbo, la denuncia al poder abusivo del franquismo y el deseo de vengar la muerte y el sometimiento de todas las Rebecas de la historia española y del film noir.

${ }^{4}$ Tomo prestado el concepto utilizado por Barbara Zecchi en su obra La pantalla sexuada, donde la autora recurre al neologismo "sexuar", derivado del italiano sessuare, para referirse a lo que en inglés se designa to gender, es decir, "marcar por el género sexual" (2014: 15). La autora sostiene que el cine español hegemónico ha estado dominado por una mirada masculina que ha privilegiado un imaginario patriarcal y ha desplazado e invisibilizado la presencia femenina delante y detrás de las cámaras. Con este volumen, Zecchi se propone historizar el cine dirigido por mujeres y estudiar sus obras fuera del imaginario patriarcal y desde un enfoque de género, esto es, "sexuándolo" de nuevo.
} 
A pesar de que el film no ofrece nuevos paradigmas representacionales, la fuerza que se le otorga al sujeto femenino le permite enfrentarse a la autoridad patriarcal y cuestionar una identidad fílmica basada en las dicotomías de género (hombre-activo-sujeto de la mirada vs. mujer-pasiva-objeto de la mirada). El desmantelamiento de la mirada masculina (male gaze) corresponde a un proyecto claramente feminista que sigue los postulados del contra-cine narrativo propuestos por Claire Johnston (1973) y Teresa De Lauretis (1987). Beltenebros ofrece una toma de conciencia de que los mitos fílmicos establecidos son producto del falogocentrismo, siendo este el primer paso para crear nuevos modelos representacionales femeninos y nuevas formas de identificación para el sujeto espectatorial.

En el nuevo universo noir que construye Pilar Miró, el cuerpo femenino sigue siendo un espacio de satisfacción del deseo sexual masculino, pero no se limita a esta función exclusivamente. También es un espacio de resistencia contra la violencia de la representación de la mujer en la pantalla y contra la violencia ejercida sobre su cuerpo que han limitado su capacidad de actuación y anulado su poder como sujeto de la historia. De esta manera, la castración ${ }^{5}$ de Ugarte/Valdivia y el incendio del cine Universal como métodos elegidos para eliminar al villano le confieren una fuerte carga política y simbólica al final de la historia diegética. En primer lugar, hay una venganza sexual por haber abusado y violado el cuerpo de las dos Rebecas. En segundo lugar, el incendio, junto a la castración, es una forma de denuncia del cine clásico y hegemónico que ha privilegiado el voyeurismo perverso para generar el placer visual masculino. Por último, el incendio y la muerte del representante del pasado represor son actos necesarios para llevar a cabo la democratización de la sociedad española. No es una guerra de sexos, sino una guerra contra el poder fálico (real y simbólico).

La historia de Beltenebros se inserta en dos momentos diferentes del franquismo, 1946 y 1962. A su vez, estos dos contextos establecen un nexo con el presente de Pilar Miró mediante la estructura de mise en abyme, puesto que ambos están caracterizados por la traición y el desencanto. Los años noventa suponen el fin de un largo enfrentamiento ideológico entre el bloque capitalista y el bloque comunista, entre el totalitarismo nacionalista y ultraconservador y el mundo socialista y democrático. Coincide con la caída del muro de Berlín, la disolución de la Unión Soviética y el auge de movimientos socialistas que exigen la recuperación de memorias olvidadas, entre ellas, de las mujeres. Los abusos de poder y las traiciones internas provocan escisiones dentro del PSOE y culminan

\footnotetext{
${ }^{5}$ El tema de la castración es una constante en el cine de Miró. Está presente en La petición, Gary Cooper que estás en los cielos, Tu nombre envenena mis sueños y El pájaro de la felicidad. Desde los estudios feministas, la castración representa un acto de venganza y justicia contra la violencia y la violación que la mujer y su imagen han sufrido en la historia del cine y en la sociedad española. Recordemos el eslogan "contra la violación, castración" promovido por el movimiento feminista español de comienzos de la Transición.
} 
en la debacle del gobierno socialista. ${ }^{6}$ Esta conexión entre la ficción y la realidad posiciona al protagonista Darman como alter ego cinematográfico de la directora. Para ello, Miró lo convierte en el héroe arrepentido que renace para llevar a cabo una venganza personal y colectiva. A este respecto, la variación que sufre el final literario muestra un cambio significativo en la caracterización del personaje masculino. En la novela, el traidor Ugarte/Valdivia muere de forma accidental al ser apuntado por la linterna que sujeta Rebeca y este, cegado por la luz, cae al vacío. Este final no ofrece ningún cambio o crecimiento en el protagonista, quien confiesa tener la misma sensación de inmovilidad, irrealidad y desorientación que al principio (Muñoz Molina, 1989: 221). No obstante, en la versión fílmica hay un duelo final entre los dos sujetos masculinos que termina con la muerte del traidor (el modelo masculino represor) en manos del protagonista (el nuevo modelo masculino). La castración como forma de darle muerte al traidor no solo redime al héroe de sus errores pasados, sino que también lo convierte en el vengador de todas las "Rebecas" que han sido víctimas de la opresión sexual y política del franquismo más degenerado.

Ann Davies señala que la vertiente retro-noir del nuevo cine negro español convierte a la femme fatale en el chivo expiatorio del bando perdedor (2009: 17). Este sujeto representa a las víctimas de la opresión franquista, cuyas voces han sido silenciadas, pero su sexualidad peligrosa fuerza al héroe a indagar en su identidad misteriosa y, por lo tanto, a superponer lo sexual y personal a lo político y colectivo. De esta manera, la mujer termina siendo el objeto de la investigación y la fuente del deseo masculino de conocimiento. Es, parafraseando a Mary A. Doane, "the figure of a certain discursive unease, a potential epistemological trauma” (1991: 1), puesto que la investigación culmina en la imposibilidad de conocer la verdad sobre el pasado español y del triunfo de la izquierda, y su presencia y su sexualidad se convierten en la verdadera amenaza para el protagonista masculino (20). Contrariamente a los postulados de Anne Davies, considero que la hibridez formal y narrativa del texto de Pilar Miró opera bajo lo que Linda Hutcheon define como "double-coded politics" (1988: 47). Si bien por un lado legitima un orden establecido - no se vislumbra ningún cambio en los acontecimientos de la historia española - , por otro lado el uso - y abuso- de las intertextualidades subrayan el artificio cultural del mito femenino. Este acercamiento posmoderno a la historia y a la representación nos remite una vez más al cuestionamiento de la supuesta naturaleza de los roles de género: "the postmodern strategy of parodic use and abuse of mass-culture representations of women, subverting them by excess, irony, and fragmented recontextualization all of which work to disrupt any passive consumption of such images" (148). El

\footnotetext{
${ }^{6}$ En 1993 el PSOE pierde la mayoría absoluta en las Cortes, a raíz de los escándalos de malversación y corrupción que involucran a financieros, políticos y a miembros del cuerpo de Policía, de las operaciones ilegales de los GAL, financiadas por altos funcionarios del Ministerio del Interior, de la recesión y del desempleo.
} 
ejercicio posmoderno en Beltenebros consiste en incitar al sujeto espectatorial a reflexionar sobre la artificiosidad de los discursos patriarcales y a entender el cine como espacio creador de mitos y de prácticas culturales que han naturalizado las dicotomías de género.

El proceso posmoderno de desenmascaramiento del pasado como un mundo ficticio o imaginado que se desarrolla en Beltenebros se inicia con la deconstrucción de los binomios culturales hegemónicos que construyen la identidad femenina en el film noir. Pilar Miró recurre al empleo de determinados recursos formales como los flashbacks, la voz en off, la posición de la cámara, el punto de vista, y el uso de intertextualidades fílmicas y literarias con el fin de apuntar a una política de género interesada en deslegitimar la posición de autoridad masculina tanto en el espacio narrativo (mostrar la capacidad de la mujer para resistir la opresión política y sexual del franquismo), como en el espacio fílmico (desnaturalizar la mirada masculina que privilegia la acción y el discurso en manos del hombre). Así pues, el juego visual, narrativo e intertextual de los dobles y de las estructuras circulares y laberínticas complica el estereotipo de la mujer traidora y castradora y le otorga una mayor complejidad a su identidad femenina.

\section{Rebeca Osorio y la reescritura femenina de la historia}

La figura de Rebeca Osorio (Geraldine James) adquiere un protagonismo significativo en la lucha clandestina de posguerra. Con ella, Miró recupera una voz política femenina y la escritura subversiva de este personaje le da visibilidad a la participación de la mujer en la lucha antifranquista. La actuación de Rebeca Osorio en el contexto bélico español rompe con las nociones masculinas de camaradería y fraternidad, conceptos que se han usado tradicionalmente para reconstruir la historia nacional desde perspectivas androcéntricas. ${ }^{7}$ Rebeca Osorio forma parte del pasado oscuro, opresivo y represivo que define la década de los cuarenta en España y que corresponde al primer viaje de Darman. Es también un aspecto de la historia personal del protagonista que este prefiere olvidar. Antes de emprender su segundo viaje a Madrid en 1962, el personaje recuerda los gritos de Rebeca Osorio rogándole que no matara a su esposo Walter, asegurándole que cometería un grave error: "Walter es un hombre leal, siempre ha luchado desde el principio. Ignoro lo que te ha traído aquí, pero no te equivoques, porque lo lamentarás toda la vida". Esta voz en off femenina, que pertenece al primer recuerdo que tiene Darman de Rebeca Osorio, está desprovista de la imagen física correspondiente y aparece como un aviso para el protagonista que está a punto de empezar su nueva misión. Esta descorporeización convierte al sujeto femenino en un espectro del pasado, en el

\footnotetext{
${ }^{7}$ Utilizo aquí el concepto de "historia" en su doble sentido, tanto el mundo diegético como la realidad extradiegética a la que alude.
} 
Zeitgeist de un trauma no resuelto. Representa a todas las voces silenciadas que se resisten a permanecer en la desmemoria, provocando el enfrentamiento del hombre con su pasado criminal.

En el segundo flashback a 1946 Darman recuerda el momento en que conoce a Rebeca Osorio. Presenciamos la primera aparición de ella como una silueta negra que avanza por el pasillo de la sala del Cine Universal, el resultado visual del contraste entre las luces blancas que emanan de la pantalla y la proyección de la cámara hacia la oscuridad de la sala. Esta imagen expresionista nos remite de nuevo a su identidad espectral y a la presentación típica de la femme fatale que emana de las tinieblas, estableciendo así un juego simbólico de la mujer con un pasado enigmático y una personalidad traicionera. ${ }^{8}$ No obstante, su actuación en la diégesis anulará esta impresión inicial, demostrando que la mujer no es una amenaza real ni para el hombre ni mucho menos para la lucha antifranquista. Su comportamiento transgrede tanto la ideología política como la moral del franquismo, ya que además de conspirar en contra del régimen, también arremete contra los valores ultra católicos del mismo al cometer adulterio. Cuando Darman descubre su relación con Valdivia, Rebeca le explica que es un acto voluntario: "No me juzgues por lo que has visto esta noche. Soy la mujer de Walter, pero tu amigo me mira, me persigue, me necesita. Está solo y herido. Es muy difícil negarle una caricia". Ante esta revelación, y ofuscado por el deseo insatisfecho, Darman pierde su confianza en ella y Valdivia aprovecha este momento de vulnerabilidad para convencerlo de que su esposo Walter es el traidor. Irónicamente, en su segundo viaje a Madrid el protagonista será culpable del mismo delito por el que condena a Rebeca Osorio, ya que estando casado se acuesta con Rebeca.

El trágico final que se le concede a Rebeca Osorio en la pantalla también difiere de su versión literaria. En la novela de Antonio Muñoz Molina, Valdivia encierra a Rebeca Osorio en una habitación y esta, según le explicará años más tarde a Darman, termina enloqueciendo. En la versión fílmica, Pilar Miró opta por el suicidio de Rebeca Osorio, según le explica Ugarte/Valdivia a Darman. Este acto, que puede verse como una derrota femenina, puede interpretarse también como una denuncia de los sistemas de opresión patriarcales o como una vía de escape (Hamilton, 1997: 201). Igualmente, el suicidio se puede entender como el último acto de resistencia al olvido de la mujer que ha sido sometida a múltiples formas de violencia durante el franquismo. De esta forma, la pervivencia de su voz y las intertextualidades fílmicas y literarias clásicas que reafirman su identidad transgresora contribuyen a definir esta forma de muerte como el último acto de rebeldía.

\footnotetext{
${ }^{8}$ Esta presentación de la mujer a partir de su silueta estilizada en la oscuridad nos remite directamente a la aparición de la femme fatale en el noir The Big Combo (Lewis, 1955).
} 
Cuando Rebeca Osorio aparece por primera vez en la sala del Cine Universal se está proyectando el western They Died with Their Boots On (Walsh, 1941). A lo largo de la trama también se incluyen escenas de las películas Mutiny on the Bounty (Lloyd, 1935) y Los últimos de Filipinas (Román, 1945). Estas referencias metafílmicas aluden a la importancia del cine como un aparato de censura estatal y una herramienta para legitimar un discurso oficial y una identidad nacional que mitifican el pasado bélico español. Asimismo, heroizan a los sujetos masculinos, mientras que la mujer queda relegada al espacio doméstico. Otro aspecto a tener en cuenta es que la presencia en el western y el cine históricobélico de figuras femeninas que refuerzan los roles de género tradicionales funciona en un primer momento como contraste con las relaciones anticonvencionales y disfuncionales del noir. Asimismo, si nos atenemos al estereotipo de la femme fatale, su intervención en el espacio público sugiere no solo un rechazo a los roles de madre y de esposa sumisa, sino que la convierte en la causante de la fragmentación de la estructura familiar burguesa. Contrariamente a lo que se esperaría, la identidad de Rebeca Osorio se nutre de otro referente fílmico, el film Rebecca, y de su fuente literaria, poniendo en tela de juicio la concepción (misógina) de la mujer como la causante de la crisis del orden social imperante.

Si nos remitimos al estudio comparativo que hace María Donapetry entre la novela de Daphne Du Maurier y la adaptación homónima de Hitchcock, descubrimos una serie de analogías entre la Rebeca de Pilar Miró y la Rebecca de Daphne Du Maurier, puesto que ambas autoras apuntan a la violencia perpetrada por el hombre llevado por sus celos. Asimismo, Donapetry sugiere que el espacio diegético es una metáfora de las ruinas de la memoria y la prisión del alma que derivan de un pasado traumático. De esta manera, las escenas del fuego de Manderley y del Cine Universal reflejan actos destructores, pero también liberadores. Representan un "exorcismo de la prisión del alma" (Donapetry, 2010: 50) y permiten a los protagonistas Maxim/Darman volver a empezar. El nexo que más conecta estas dos historias reside en el tratamiento de la muerte de Rebec(c)a, la mujer convertida en un fantasma del pasado no resuelto. En la novela de Daphne Du Maurier, así como en su adaptación fílmica, se descubre que Rebecca le era infiel a su marido y la noche de su muerte le confiesa al señor de Winter que está embarazada de otro hombre. Mientras que en la novela se infiere que Maxim mata a su esposa llevado por los celos, en la película el esposo es testigo del golpe mortal y accidental que sufre Rebecca. La posición moral y ética que sugiere el film - producto de la decisión del director, el productor y el código Hays - difiere enormemente de la postura que ofrece el texto literario, donde se descubre que, tras recibir noticias del médico sobre su cáncer y los pocos meses de vida que le quedan, Rebecca provoca su propia muerte (Donapetry, 2010: 50). La muerte accidental del film funciona como un acto de justicia poética que le permite al señor de Winter retornar al orden patriarcal. Una vez absuelto de cualquier culpabilidad y liberado de la penitencia (au- 
to)impuesta por la muerte de su primera esposa, recupera su autoridad y, con ella, a su nueva esposa. La intertextualidad literaria de Rebecca nos permite recuperar no solo la voz de una heroína silenciada, sino también la voz transgresora de su autora. Si bien la novela recurre a muchos convencionalismos de la novela gótica y sentimental, la escritora construye personajes femeninos que transgreden los roles y espacios asignados por el patriarcado. Un proceso similar ocurre en la adaptación de Beltenebros. En el film, la voz autorial femenina de Rebeca Osorio está presente mediante el sonido de su máquina de escribir mientras Darman y Valdivia hablan sobre sus experiencias durante la guerra antifranquista y las desilusiones sufridas. Este personaje femenino, creador de historias, se convierte por contaminación metonímica en el alter ego de la directora. A su vez, la intervención de más de una voz narrativa dentro de la diégesis es otro intento por desmasculinizar el discurso oficial de la historia que privilegia la voz masculina.

\section{Gilda o Rebeca: la destrucción del voyeurismo perverso noir}

La segunda representación femenina que analizaremos corresponde a la de la joven Rebeca (Patsy Kensit), una mujer cuyo nombre, parecido físico y otras coincidencias establecen una relación (real y/o simbólica) con la desaparecida Rebeca Osorio. Al igual que su antecesora, esta atractiva cantante y bailarina es sometida al poder abusivo del franquismo (representado en la figura del comisario Ugarte) y lucha con todas sus armas por mantener el control de su cuerpo y de su imagen. El empoderamiento que recibe este personaje también procede de las intertextualidades intradiegéticas con el aclamado film Gilda (Vidor, 1946). Asimismo, su identidad se nutre del discurso extradiegético proveniente de la propia Patsy Kensit, una célebre actriz y cantante británica en el momento del rodaje y estreno. A partir de los diferentes niveles de lectura derivados del texto fílmico y de las interrelaciones fílmicas y culturales, se construye una red compleja de significados que configuran la identidad de Rebeca.

El intertexto fílmico Gilda también permite transferir el escenario fascista creado por King Vidor al territorio español, sacando a relucir el mundo criminal y corrupto clandestino del Madrid franquista. Según Kathleen Vernon (1997: 50), Gilda es un referente político e histórico de la posguerra que forma parte de la "cultura de evasión", a la vez que es un transmisor de memorias individuales y colectivas de un periodo que evoca la represión moral y el control social por parte del gobierno, de la iglesia y de la familia. ${ }^{9}$ Tanto Kathleen Vernon como Richard Dyer (1998) sugieren que la transposición de Gilda/Hayworth al

\footnotetext{
${ }^{9}$ Cuando la película se estrena en la capital, el sector más conservador de la Falange decide censurarla porque su contenido difiere de la imagen ultraconservadora e idealizada de la mujer y de la sociedad que el régimen quiere fomentar a través de la cultura.
} 
territorio español actúa como una fuerza que desestabiliza los roles de género pero que, en última instancia, no ofrece ningún cambio (Vernon, 1997: 53-54). No obstante, la recuperación del personaje de Gilda en Beltenebros es más que el simple recuerdo de una sex symbol con el único propósito de satisfacer al espectador del neo-noir. Para entender la función transgresora que tiene la recuperación de Gilda es fundamental tener en cuenta el rol del carismático personaje de Patsy Kensit en el proceso de recepción del espectador de los noventa.

Efectivamente, los llamados star studies ponen de manifiesto la importancia que tienen las estrellas en el proceso de significación fílmica, el potencial que muchas de ellas aprovechan para escapar de determinadas interpretaciones (Dyer, 1998: 115) y la relevancia de la intervención del espectador a la hora de construir el significado y recibir los films como proyectos individuales y como parte de un corpus fílmico (Vernon, 1997: 52). El trabajo pionero de Molly Haskell nos recuerda los modos en que Hollywood estereotipó, glorificó y traicionó a las mujeres "to keep women in their place" (1987: 3). ${ }^{10} \mathrm{M}^{\mathrm{a}}$ del Carmen Rodríguez Fernández explica al respecto:

El Star System provocó que cada estudio tuviera a sus actores y actrices en propiedad y se especializaran en un género cinematográfico. A medio plazo, esto significó la asociación de aquellos con unos papeles personalizados que, sustentados por una sociedad patriarcal, contribuyeron a la creación de arquetipos femeninos, identificados a su vez, en muchos casos, con las vidas privadas de las actrices. (2006: 14)

En la creación de Gilda, explica Richard Dyer (1998: 116), la imagen autorial o la persona de la actriz Rita Hayworth creó cierta dificultad a la hora de encasillarla como femme fatale. A pesar de las exigencias del género y de las restricciones del código de censura, el bagaje artístico de la belle Rita Hayworth desafiaba cualquier intento de relacionar a sus personajes con una identidad negativa, fálica y destructora, y le permitió construir una imagen potente que se resistía a una determinada categorización. Su imagen visual, como expresión erótica, la convertía en una proyección de la fantasía masculina, mientras que su talento como cantante y bailarina le permitía realizar un número musical que se convertiría en su forma de autoexpresión. También facilitaría la identificación con la mujer espectadora, no solo como ideal de belleza, sino también como representante de sus mismas preocupaciones (120). Como ya ha apuntado la crítica fílmica feminista, la actuación en solitario de la famosa canción "Put the Blame on Mame" otorga a Gilda un momento de privacidad para expresar su

\footnotetext{
${ }^{10}$ Su obra From Reverence to Rape. The Treatment of Women in the Movies revela cómo la industria de Hollywood en los años cuarenta estaba monopolizada por los estudios y por un sistema de contratación que limitaba la libertad de expresión de los actores y actrices.
} 
frustración frente al hombre que culpa a la mujer de cualquier desastre natural. La segunda representación que esta hace en público es un desafío a la imagen que el sistema patriarcal ofrece de la mujer, mientras que la primera actuación en solitario es un lamento personal por la violencia que sufre en manos del hombre y por la imposición de unos roles indeseados. En el contexto norteamericano de posguerra, era necesario un final conservador que promoviera la retirada de la mujer del espacio público y la obligara a regresar al doméstico, concebido como el lugar privilegiado para la mujer virtuosa. Sin embargo, en el imaginario espectatorial, Gilda ha permanecido como la heroína que se rebela ante las injusticias del sexismo institucionalizado. Como indica Janey Place, "the final lesson of the myth often fades into the background and we retain the image of the erotic, strong, unrepressed (if destructive) woman" (1998: 48). Por lo tanto, la imagen extrafílmica de Hayworth cuestiona o impide la lectura de Gilda como una mujer fatal que termina siendo redimida por el hombre y el sistema patriarcal.

En Beltenebros, la relación Kensit/Rebeca se construye a partir de códigos similares. Al igual que Hayworth, Kensit desarrolla carreras paralelas como cantante y actriz. Su carisma deriva de la atracción sexual que su cuerpo y voz provocan, y el placer que obtiene al actuar y exhibir su belleza natural se traslada a la pantalla para cargar al personaje de una sexualidad activa. Siguiendo una estructura visual y narrativa similar a la de Gilda, la actuación de la protagonista en Beltenebros se divide en dos actos. El primero se ciñe a imitar los códigos fílmicos tradicionales que sitúan a la mujer en el centro de la pantalla para satisfacer el placer visual masculino mediante el erotismo que su imagen y sus gestos generan. Rebeca, al igual que Kensit, disfruta al ser deseada, siempre y cuando ella mantenga el control de su cuerpo e imagen. Así lo expone Hamilton: "In real life, Kensit delights in her celebrity status and her desire for fame has been widely reported in interviews dating from her childhood roles" (1997: 323). En el segundo acto, Rebeca se quita el vestido y el desnudo que le impone la directora - que Kensit en un principio rechaza- no es gratuito y forma parte de la agenda política de la directora: cuestionar el voyeurismo perverso del cine noir, y por ende el cine hegemónico, a la hora de representar al sujeto femenino.

Rebeca, al igual que Gilda, se resiste a ser categorizada como un objeto sexual, y el club en el que trabaja, la Boite Tabú, metáfora espacial del sexo femenino y proyección del imaginario sexual masculino, se convierte en su campo de batalla. Entrar en el club significa convertirse en un voyerista de lo prohibido, en este caso, del cuerpo desnudo de la joven. Darman entra a formar parte del público diegético "masculino", pero Ugarte/Valdivia es el máximo representante del voyeurismo más degradante, puesto que obliga a Rebeca a satisfacer su placer visual y su apetito sexual. Las gafas oscuras tras las que esconde su verdadera identidad, junto al cigarro que lleva constantemente en la boca son los elementos que no solo contribuyen a definir una identidad fálica y 
corrupta (castradora), sino que también refuerzan su masculinidad castrada. ${ }^{11}$ Cuando Rebeca, el objeto deseado, aparece en el escenario del club, la cámara se sitúa en el mismo lugar en el que Ugarte/Valdivia está sentado. Un plano general en picado establece una correspondencia entre la mirada del sujeto (masculino) deseante y el espectáculo del sujeto (femenino) deseado. En la siguiente toma, un plano general frontal enfoca a Rebeca mientras canta y se acerca al público con gestos seductores. Su pelo largo y pelirrojo, su vestido negro ceñido y los guantes largos son los tres elementos que la convierten en la copia exacta de Gilda, icono cultural de la sensualidad y feminidad. Más adelante descubrimos que las pelucas que lleva la joven no son más que máscaras. Estas no funcionan como un tropo noir que esconde su poder castrador. Más bien, son una herramienta que le permite actuar y sobrevivir a la violencia del franquismo. En otra ocasión, presenciamos cómo Ugarte/Valdivia la obliga a llevarlas para satisfacer sus fantasías sexuales.

Al igual que sucede con el número musical de Gilda, los paneos de la cámara de derecha a izquierda siguen los movimientos de la cantante, permitiendo que el espectador goce de su cuerpo atractivo y sus gestos seductores. Seguidamente, un primer plano de su rostro muestra a Rebeca dirigiendo su mirada a la cámara. El uso de una luz suave evita la creación de sombras en la cara y elimina cualquier rastro de la maldad que simbólicamente presentan los rostros femeninos en el noir, construidos mediante el empleo de una luz dura. Contrario a ello, su mirada pícara revela una sensualidad inocente que permite al espectador (convertido en voyerista) disfrutar de lo que está viendo sin sentirse amenazado. La imitación de Rita Hayworth en el famoso número de los guantes concluye con un plano medio de Rebeca quitándose el guante derecho y realizando movimientos sensuales que la acercan y alejan de la cámara. Hasta aquí todo indica que Miró está jugando con las reglas del noir. La segunda parte del espectáculo corresponde a un striptease propio del cine neo-noir de los noventa. Comienza con un primer plano de Ugarte/Valdivia, que se deleita fumando y contemplando a la artista desde su palco. La oscuridad le permite tener una experiencia verdaderamente escoptofílica, pues disfruta del placer de mirar sin ser mirado. Rebeca sigue desvistiéndose, pero un primer plano en picado de su cara muestra una mirada fría y desafiante dirigida al hombre que la obliga a humillarse. Cuando la joven se quita el vestido, ofreciendo un desnudo que se prolonga por seis segundos, un primer plano de la mirada inquisidora de Darman contrasta con la exaltación del

\footnotetext{
${ }^{11}$ El noir se ha entendido como un espacio en el que se exponen los diferentes tipos de crisis de masculinidad. Para ello, la identidad del héroe se diferencia muchas veces de la de su antagonista mediante la falta de movilidad de este último. Esta característica funciona como un tropo del trauma sexual o refuerza la imagen arquetípica del villano "degradado". En Gilda el bastón que acompaña a Ballin representa su poder fálico pero también su falta de virilidad masculina. Este elemento equivaldría a las gafas oscuras y al cigarro que forman parte de la doble identidad, corrupta e impotente, del villano de Beltenebros.
} 
público presente, mayoritariamente masculino. Antes de que finalice el espectáculo, este abandona la sala.

Una lectura superficial sugiere que esta escena forma parte de un producto neo-noir que sigue reproduciendo la mirada masculina que se adapta a los placeres visuales del nuevo sujeto espectatorial. Asimismo, el estilo visual, la iconografía explícitamente sexual y la puesta en escena explotan el glamour y la sensualidad de Rebeca, transformándola en el nuevo icono sexual de los noventa, donde la nueva femme fatale es una "sexual performer" (Hanson, 2007: 169). Frente a esta lectura, es posible una contra-lectura gracias a la participación activa de una audiencia "cómplice", capaz de interpretar la función transgresora de la intertextualidad con Gilda. Para este fin, son relevantes los primeros planos del rostro de Rebeca devolviéndole la mirada al villano y que exponen su fortaleza, al igual que su vulnerabilidad. También es importante la escena que sigue al striptease, en la que la actriz regresa a su vestuario y procede a quitarse el "disfraz" de Gilda: se quita el maquillaje, las pestañas postizas y la peluca. El acto de desnudarse, es decir, de quitarse la peluca, el vestido y demás complementos, es un acto de liberación de las máscaras impuestas y de rechazo a una identidad femenina (la de femme fatale) arquetípica y artificial. Según explica Mary Anne Doane, el relato de Gilda "takes the form of a striptease, peeling away the layers of Gilda's disguises in order to reveal the good woman underneath, the one who will go home with Johnny" (1991: 107). En otras palabras, el desnudo es un acto epistemológico que lleva al héroe a descubrir la verdadera identidad del sujeto femenino, con lo cual se deduce que el rol de la femme fatale no es más que un acto performativo impuesto por una autoridad masculina. Una contra-lectura también sugiere que los diferentes "desnudos" que sufre Rebeca reflejan una vez más el rechazo de Pilar Miró a la cosificación que sufre constantemente el cuerpo femenino en el cine dominante y, particularmente, en el noir.

El supuesto final feliz de Beltenebros quedaría, no obstante, cuestionado por la crítica feminista debido a los paralelismos que se pueden establecer con la película de King Vidor. Tanto Darman como Johnny recurren a la violencia (ambos abofetean a las protagonistas) cuando su autoridad se ve amenazada y su masculinidad es menospreciada. Igualmente, el "Let's go home" de Gilda, que implica una vuelta al hogar de la mujer y la restauración del orden familiar tradicional, equivaldría a la respuesta que Darman da a Rebeca cuando esta le pregunta “¿Adónde voy a ir yo?" y él le contesta "Adonde yo vaya." Si bien es verdad que Darman representa un modelo masculino afín a la democracia, el final que ofrece Pilar Miró sigue privilegiando un orden patriarcal, donde la mujer debe someterse a los designios del (nuevo) hombre. 


\section{REFERENCIAS BIBLIOGRÁFICAS}

Davies, Anne (2009), "Criminality and the Left in Spanish Retro Noir Films", Journal of Iberian and Latin American Studies, 15, 1: 15-28.

De Lauretis, Teresa (1987), Technologies of Gender. Essays on Theory, Film and Fiction, Bloomington \& Indianapolis, Indiana University Press.

Doane, Mary Anne (1991), Femmes Fatales: Feminism, Film Theory, Psychoanalysis, Nueva York, Routledge.

Donapetry, María (2010), "Las ruinas y las sombras de Manderley", Arbor: ciencia, pensamiento y cultura, 741: 43-52.

Du Maurier, Daphne (1938), Rebecca, Londres, Victor Gollancz.

Dyer, Richard (1998), "Resistance through Charisma: Rita Hayworth and Gilda", Women in Film Noir, E. Ann Kaplan (ed.), Londres, British Film Institute: 115-122. [1978]

Galán, Diego (2006), Pilar Miró: Nadie me enseñó a vivir, Barcelona, Plaza \& Janés.

Hamilton, Jayne (1997), Gender Representation and Textual Strategies in the Films of Pilar Miró, Newcastle upon Tyne, University of Newcastle upon Tyne.

Hanson, Helen (2007), Hollywood Heroines: Women in Film Noir and the Female Gothic Noir, Nueva York, I.B.Tauris.

Haskell, Molly (1987), From Reverence to Rape. The Treatment of Women in the Movies, Chicago \& Londres, The University of Chicago Press. [1973]

Hutcheon, Linda (1988), A Poetics of Postmodernism: History, Theory, Fiction, Nueva York, Routledge.

Johnston, Claire (2000), "Women's Cinema as Counter-Cinema", Feminism and Film, E. Ann Kaplan (ed.), Oxford, Oxford University Press: 22-33.

Jordan, Barry y Rikki Morgan-Tamasunas (2001), Contemporary Spanish Cine$m a$, Manchester, Manchester University Press.

Kaplan, E. Ann (ed.) (1998), Women in Film Noir, Londres, British Film Institute. [1978]

Muñoz-Molina, Antonio (1989), Beltenebros, Barcelona, Seix Barral.

Place, Janey (1998), "Women in Film Noir", Women in Film Noir, E. Ann Kaplan (ed.), Londres, British Film Institute: 47-68. [1978]

Rodríguez Fernández, Ma del Carmen (2006), “Introducción”, Diosas del celuloide: arquetipos de género en el cine clásico, $\mathrm{M}^{\mathrm{a}}$ del Carmen Rodríguez Fernández (ed.), Madrid, Jaguar: 11-24.

Rolph, Wendy (1995), "Desire in the Dark: Beltenebros Goes to the Movies", Revista canadiense de estudios hispánicos, 20, 1: 117-125.

Vernon, Kathleen (1997), "Reading Hollywood In/And Spanish Cinema: From Trade Wars to Transculturation", Refiguring Spain: Cinema/Medial 
Representation, Marsha Kinder (ed.), Durham, Duke University Press: 35-64. Zecchi, Barbara (2014), Desenfocadas. Cineastas españolas y discursos de género, Barcelona, Icaria.

\section{FILMOGRAFÍA}

Hitchock, Alfred (dir.) (1940), Rebecca, Selznick International Pictures.

Miró, Pilar (dir.) (1991), Beltenebros, Iberoamericana Films.

Vidor, Charles (dir.) (1946), Gilda, Columbia Pictures.

\section{(c) (i) (ㅇ) $€$}

